\title{
APROXIMACIONES A LA PERSPECTIVA DE LA HISTORIA AMBIENTAL PARA REFLEXIONAR SOBRE LA HISTORIA PATAGÓNICA ARGENTINA*
}

\author{
APPROACHES TO HISTORICAL ENVIRONMENTAL PERSPECTIVE \\ TO REFLECT ABOUT HISTORY OF ARGENTINEAN PATAGONIA
}

\author{
Paula Gabriela Núñez**
}

\begin{abstract}
Este trabajo explora la historia y la historiografía patagónica. Para ello, parte de entender la Patagonia como territorio de integración tardía de América Latina y propone abrir diálogos con la historia ambiental. La investigación analiza el modo en que la historia ha tomado o soslayado el determinismo ambiental de los documentos estatales, reflexionando acerca de los aportes potenciales de una perspectiva inscripta en la historia ambiental. Este trabajo busca presentar investigaciones patagónicas actuales, en contacto con investigaciones relativas a estudios en territorios de integración tardía en otros espacios, y con ello aportar a una mirada tendiente a la creación de un marco teórico que reúna dinámicas hasta ahora escindidas entre lo social y lo natural.

Palabras claves: Historia ambiental; historia patagónica; territorios de integración tardía; Argentina.

This paper explores the Patagonian history and historiography. It part of understanding Patagonia as a later integrated territory of Latin America and aim to open dialogues with environmental history. The research covers the way in which the imprint of the environmental determinism of state documents is taken or ignored by History, reflecting on the potential contributions of an inscribed perspective in environmental history. This work contributes to make a general presentation of Patagonian researchers that serves to put it in contact with research related to studies other later integrated territories, and with this, contribute to a perspective tending towards the creation of a theoretical framework that brings together dynamics that until now have been split between the social and the natural.
\end{abstract}

Key words: Environmental History; Patagonian History; Later integrated territories; Argentina.

\section{Introducción}

El presente trabajo indaga la historia y la historiografía patagónica desde la complejidad adquirida por las dinámicas estatales en sus fronteras. En Latinoamérica Serjé (2005) plantea que las fronteras son fértiles para pensar lo estatal, pues allí se configura desde visiones, intereses y prácticas de grupos particulares que tienen acceso a "ser" el Estado. La autora, mirando Colombia, propone que la naturaleza y las poblaciones son presentadas desde intereses sectoriales cambiantes en dinámicas reconocidas en múltiples escenarios (Soluri et al. 2019; Núñez 2013; Klubock 2014).

La Patagonia resulta un territorio de frontera en muchos sentidos. Pues no solo contiene una frontera estatal que separa Argentina de Chile, sino que ha sido construida como exotismo lejano por ser un territorio de "integración tardía", incorporándose a los órdenes estatales argentino y chileno cuando la política interna estaba estabilizada y los espacios metropolitanos estaban conformados. Núñez (2013) observa cómo la cordillera tomada como límite aparece en la literatura estatal como muralla, ignorando deliberadamente los dinamismos de intercambio que la propia geografía propiciaba por los profundos valles transversales patagónicos, universalizando particularidades de la cordillera en el norte de ambos países (Mendonca, 2017), donde igualmente el tránsito es continuo. Navarro (2011) reconoce la politización de la idea de desierto que adjetiva a la Patagonia, heredada de la noción sarmientina como sinónimo de barbarie (Sarmiento 1874) y entonces inscripta en el modelo de país en desarrollo. Ello acerca la historia ambiental al tema del artículo, pues el deslizamiento de la geología y la botánica a la política ha sido naturalizador de desvalorizaciones y extractivismos (Gallini, 2005).

\footnotetext{
* $\quad$ Resultado del PI UNRN 40-B-786.

** Universidad de Los Lagos / Universidad Nacional de Río Negro: Instituto de Investigación en Diversidad Cultural y Procesos de Cambio, CONICET Bariloche, Argentina. Dirección postal Alsasia 1177. Dto 1208. Osorno, Chile.

Correo electrónico: paula.nunez@ulagos.cl
} 
En su recorrido por la historia ambiental, McNeill (2005) reconoce tres aproximaciones, 1 : el enfoque material, que hace hincapié en los cambios en los ambientes físicos y biológicos y la forma cómo esos cambios afectan las sociedades humanas; 2: el enfoque cultural-intelectual, que observa la construcción de imágenes y representaciones que median en los vínculos entre las sociedades y sus ambientes, y 3 : el enfoque político, basado en el análisis de políticas públicas y conflictos. Este último es, a decir del autor, la historia ambiental más adoptada por historiadores pues encaja con la utilización del Estado-nación como unidad de análisis. McNeill reclama atención respecto de la primera aproximación que cuenta con antecedentes en cruces entre historias climáticas y sociales (Tapia 2017) pero sin tantas referencias a otras materialidades. En este artículo interpelamos la historiografía patagónica desde esta demanda. El artículo busca recorrer elementos de historia ambiental para comprender la consolidación de los imaginarios impuestos sobre las áreas de integración tardía. La Patagonia ha sido reducida a la idea de naturaleza pura, animalizando poblaciones nativas y migrantes (Núñez et al., 2019) o reconociéndola como soporte de recursos extraíbles (Bachiller 2019). Para ello, la primera sección del escrito recorre el ordenamiento territorial patagónico, analizando el desarrollo y gestión del territorio a partir de planificaciones estatales establecidas en torno al objetivo del desarrollo regional. La segunda, avanza hacia la historiografía patagónica, considerando los principales referentes. La tercera, sistematiza lo recortado como historia ambiental patagónica. Se cierra con conclusiones que abordan la pregunta por los territorios de integración tardía a la luz de lo expuesto.

\section{El ordenamiento territorial de la Patagonia}

La Patagonia es la región continental sur de América Latina. Es un territorio actualmente administrado por los Estados argentino y chileno, pero que hasta mediados del siglo XIX estuvo mayormente organizado por pobladores originarios.

Las referencias estatales al territorio apelaron al ambiente como determinante de la población, justificando la desvalorización de la misma (Núñez 2019; Navarro 2011; Núñez 2013), como en otros espacios latinoamericanos (Trejo 2011, Soluri et al. 2019; Diegues 2005). Si bien se trata de un espacio binacional, por motivos de extensión, profundizaremos en escritos y procesos argentinos sin perder de vista las articulaciones con Chile. Girbal (2008) indica que el territorio argentino debe ser entendido desde tres lógicas organizacionales, la de la zona central, ligada a la provincia de Buenos Aires, la de las provincias históricas, organizadas desde administraciones coloniales preexistentes al país, y la de los territorios nacionales, integrados a partir de la resolución de los conflictos entre el espacio central y los ámbitos provinciales en 1853. De hecho, el control de la Patagonia comienza a legislarse en $1862^{1}$, pero el dominio efectivo se resolvió con la controvertida campaña militar de 1879 (Navarro 2004) autodenominada "Campaña al Río Negro", focalizada en el norte de la Patagonia, y conocida como "Campaña al desierto". Este avance, que resultó en el desmantelamiento del control territorial de pueblos originarios, aparece sistemáticamente en estudios posteriores, en tanto establece una modalidad específica de avance estatal, y una caracterización del espacio como vacío, a pesar de contar con población.

Navarro (2011) señala que la noción de desierto que adjetiva a la Patagonia operó en Argentina como un programa de gobierno, que justificaba el control apelando a la idea de vacío de población moderna. En Chile acontece una construcción similar más al sur, en el reconocimiento de la zona de Aysén y estrecho de Magallanes (Chiuminatto y del Río, 2016; Núñez et al. 2016), evidenciando la artificialidad de la construcción política del ambiente. El desierto como programa planteaba que la presencia estatal convertiría ese vacío en un vergel. En Argentina, en1884 el Congreso sancionó la Ley 1532, creando nueve Territorios Nacionales: Misiones, Formosa, Chaco, La Pampa, Neuquén, Río Negro, Chubut, Santa Cruz y Tierra del Fuego, los seis últimos correspondientes al territorio patagónico. Esta construcción administrativa desconoció la población originaria y el orden colonial previo (Buscaglia y Bianchi 2016), planteando un origen absoluto en la administración argentina.

Las escasas políticas estatales de infraestructura postconquista reconocen distintos hitos organizacionales con diferentes reconocimientos de un mismo paisaje. Uno fue el reparto de tierras para promover la explotación ovina. En pocos años gran parte de la superficie patagónica se dividió en extensas estancias ofrecidas a capitales británicos con emprendimientos de exportación de lanas (Coronato 2010). La Patagonia argentina 
fue presentada como naturalmente destinada a un animal introducido, la oveja.

Otro hito fue la firma por el acuerdo de los límites con Chile en 1902, en un proceso donde se acordó la apertura de fronteras, favoreciendo la migración chilena a la colonización de territorios argentinos (Bandieri 2005), donde los valles transversales de la cordillera se presentaron como "pasos naturales".

Un tercer hito tiene que ver con los recursos. Hay descubrimientos de petróleo en 1907 en Comodoro Rivadavia (Chubut) y en 1918 en Plaza Huincul y Cutral Co (Neuquén). En medio encontramos el primer estudio sistemático acerca de los recursos acuíferos y mineros norpatagónicos del norteamericano Bailey Willis (1914), contratado por el Ministerio de Obras Públicas para evaluar posibles explotaciones en el área (Navarro 2007). La Patagonia es presentada como recurso energético y a partir de la década del 20 son los recursos a tutelar, antes que los pobladores, las referencias para definir política.

Como contracara, en el mismo período, los Andes patagónicos se presentan como paisaje intocado (Diegues 2005) desde 1922, con la creación del Parque Nacional del Sud, en la región del Nahuel Huapi. Esta construcción modifica sustancialmente la noción de paisaje. Los movimientos naturales devinieron antagónicos en un proceso de cierre de fronteras con Chile que se ligó a la descripción de los árboles (Núñez y Lema 2019). El ambiente se presentó como argumento autoevidente de la política que se llevaba adelante (Nouzeillies 1999), tanto para el cuidado como para el extractivismo, en perspectivas similares a las de otras regiones, profundizado por las tardías legislaciones ambientales (Escalona 2020). En la zona andina, esto se profundizó en 1934, con la sanción de la ley Nacional de Parques Nacionales (Ley 12.103) que redenominó al parque nacional del sud como Parque Nacional Nahuel Huapi, concentrando las áreas protegidas de Argentina en los Andes patagónicos hasta mediados del siglo XX.

La desnaturalización del movimiento poblacional se liga también a la apertura del canal de Panamá en 1914 que implicó la pérdida de relevancia geopolítica del área de Magallanes como contacto entre el Atlántico y el Pacífico. En Chile, varios puertos dejaron de ser internacionales al tiempo que avanzaba el control por parte de los Estados argentino y chileno, que disminuyeron autonomías logradas al desmantelar redes económicas establecidas desde una perspectiva binacional (Méndez 2010). Como un contrapunto, en la naciente del río Negro se propició la fruticultura desde la década del 30 en una estrategia que ataba la economía de la región patagónica argentina a Buenos Aires (Bandieri 2005; Blanco 2008). Así, como una síntesis de la primera mitad del siglo XX, encontramos un territorio mayormente reducido a recursos a extraer y a paisajes monumentales considerados vacíos, con enormes diferencias internas, pero siempre explicada desde el paisaje antes que desde sus pobladores.

Desde el paisaje se justificó la necesidad de tutelaje político resuelta con la figura de los "Territorios nacionales". Estos eran territorios habitados por pobladores sin derechos a elegir gobernantes fuera de la escala municipal (Ruffini y Blancha 2013; Iuorno y Crespo 2008, Arias 2010). Las políticas de desarrollo y las vías de comercio se subordinaban a proyectos nacionales que no tenía a la Patagonia entre sus motores de crecimiento, excepto como la extracción energética. Si bien esto se comienza a modificar en 1955, aún hoy se reconocen dinámicas de dependencia y permanece el imaginario del destino extractivista (Bachiller 2019; Llosa 2020; Trpin y Rodríguez 2018, entre otros), así como racismos y sexismos, pues a pesar de décadas de políticas de integración, se sostienen argumentos donde el ambiente y los migrantes aparecen como responsables de las contradicciones. Por ello la pregunta por la escritura de la historia permitirá hacer complejos relatos que aun justifican desigualdades en una integración tardía que tiene más de cien años.

\section{La historiografía patagónica}

Los relatos históricos nacionales se han centrado en los espacios más tempranamente organizados, vinculados con la concentración de poder, tanto económico como político. Los espacios fronterizos marginales no solo han sido menos estudiados, sino que se describieron como vacíos, porque la población existente, por vivir en esos espacios, fue caracterizada en términos de barbarie hasta mediados del siglo XX, cuando la civilización parecía resolverse en los espacios urbanos. Este modo descriptivo se reconoce en todos los márgenes latinoamericanos, Serjé ubica un ejemplo en las selvas colombianas. Trejo hace lo propio con el desierto de Sonora, en México. Diegues lo plantea para la selva amazónica. Gordillo (2010) reconoce el argumento de la barbarie en el norte argentino y Cunil (2014) lo explora en las zonas áridas de los 
Andes. La especificidad patagónica, indagada en Argentina (Navarro 2011) y Chile (Núñez et al. 2017, Harambour y Barrena 2019), plantean elementos comunes a los casos citados:

1. La superposición de jurisdicciones en territorios descriptos como vacíos. Pues encontramos solapamientos de diferentes intereses nacionales en disputa.

2. El reconocimiento territorial en términos de recursos disponibles y desaprovechados.

3. La llegada de capitales confundida con el control estatal y el delineamiento del manejo del espacio desde modelos gestados en espacios centrales, desconociendo las particularidades del territorio.

4. El Estado local constituido desde visiones, intereses y prácticas de grupos particulares que tienen acceso a "ser" ese Estado.

La superposición de jurisdicciones es uno de los temas más estudiados de la historiografía patagónica (Rey 2005; Bandieri 2005; Blanco 2008; Méndez y Muñoz 2013; Coronato 2010). La misma muestra que los tiempos locales no se reducen a los nacionales, además de la necesidad de cruzar las dinámicas argentinas y chilenas, que en esta región se co-constituyen en forma permanente. Estos debates difícilmente presenten arraigos por fuera de la presencia estatal, pero sí destacan el peso de las influencias transcordilleranas, que se explicitan como agencias económicas que no se agotan ni restringen a los límites nacionales. Desde el capital se explica la reconstitución de las fronteras, ya entrado el siglo XX (Méndez y Muñoz 2013). Esto se solapa, como palimpsesto, con la constitución de los parques nacionales, pensados para el descanso de esos mismos capitalistas (Diegues 2005; Bessera 2011; Klubock 2014; Fortunato 2005; Picone 2019).

La historia económica introduce un elemento más. A diferencia de la costa vinculada al proceso colonial, la Patagonia andina y central se asocia a la organización estatal americana. Desde aquí, el inicio de la historia es la campaña militar de 1879, a partir de esta se establecen las distribuciones de tierra, que la mayor parte de la historiografía regional toma de anclaje para reconocer agencias económicas donde propiedad privada e individualismo resultan en estructura y no en variable de los procesos estudiados.
Hay una separación entre los estudios vinculados a pueblos originarios de aquellos ligados a estudios estatales, construyendo la ilusión de un origen del espacio en las formas estatales. Buscaglia y Bianchi (2016) indican que en Patagonia esto parece sostenerse en el relato acerca de la costa. La población originaria y las prácticas de integración quedaron fuera del relato de los asentamientos coloniales. Zusman (2001) reconoce intercambios patagónicos en el siglo XVIII que repiten patrones españoles, y que demandan una historia más compleja.

Un ejemplo de valoración de población migrante europea en la historiografía patagónica está en el reconocimiento del asentamiento galés que arribó a las costas de la actual provincia de Chubut en 1865, cuando la administración argentina no tenía control sobre el territorio. Los galeses fueron tomados con un "... estatus de agente civilizador... consolidador de soberanía y referencia de las fronteras territoriales" (Williams y Baeza 2018).

La idea de "agente civilizador" expone los sesgos valorativos asociados al reconocimiento de un tipo específico de "agentes del desarrollo". Las nociones de "pioneros" y "prohombres" recurren a singularidades descriptas desde el heroísmo personal. Esto pone a la luz una matriz racista y androcéntrica que ubica la comprensión del territorio en un cruce con el sentido del tiempo (Palacio 2002). En el caso patagónico el tiempo del progreso estuvo marcado por el comercio internacional ligado a la producción lanera que se tomó como modelo de desarrollo en el inicio de la apropiación territorial.

Esto nos lleva al análisis del capital de inversión, cumpliendo el doble rol de ordenador del territorio y disciplinador social, entrelazando los capitales a la conformación de la institucionalidad en el territorio. Los estudios agrarios, vinculados al mundo del trabajo, se han detenido en estos aspectos mostrando la necesidad de hacer complejas agencias en este espacio de estudio (Bendiny y Tsakomagkos 2000, Trpin y Álvaro 2014; Harambour y Barrena 2019).

La estatalidad adopta un carácter cambiante que explica las diferentes posiciones desde el propio entorno, que deviene en argumento político. El Estado llegando en forma "incompleta" se repite en los estudios patagónicos (Sarobe 1935; Navarro 2011; Pérez 2011; Carrizo 2009; Favaro 1999), que entonces presupone la existencia completa en algún otro espacio. Ahora bien, esas "incompletitudes" resultaron funcionales a las desigualdades y asimetrías analizadas en estos mismos textos. Podría 
pensarse que el Estado ejerce soberanía en anclajes constitutivos de lo consolidado como frontera marginal, así como los anclajes de materialidad a los que refiere un Estado presente en el entorno y ausente en las instituciones.

De aquí resulta central la pregunta por los sentidos del ambiente. Vezub (2009) explora la existencia de elementos biológicos y políticos en órdenes previos a los estatales al problematizar la "Gobernación Indígena de Las Manzanas" postulada por el cacique patagónico Valentín Saygüeque a inicios del siglo XIX, como una interpelación política para dar cuenta de una administración existente, apoyada en acuerdos con Argentina y en dinamismos de gobernabilidad mapuche. Destaca la referencia a "las manzanas" como la apelación biofísica a una adscripción indígena, que liga una pertenencia a una planta introducida, transformada en categoría política. Foester y Vezub (2011) analizan los anclajes biológicos de lo político en las diversas articulaciones que en la Patagonia central y andina del siglo XIX continúan las complejas dinámicas de intercambio y enfrentamiento que Zusman reconocía para el área de la costa en el siglo XVIII. Los autores marcan que estos procesos de intercambio se omiten frente a la mirada exclusiva acerca de conflictos leídos como antagónicos, que pierden de vista los cruces de sentido, donde lo biológico y lo social se confunden y matizan.

Sourrouille y Vezub (2014) reconocen en la historiografía patagónica una sobredimensión del conflicto como explicación excluyente, y que se ha criticado en la historiografía de otros territorios de integración tardía (Ulloa 2004; Gallini 2005). Esto muestra la dificultad para superar el antagonismo sociedad/naturaleza en la mayor parte de los estudios patagónicos, que replican el imaginario moderno en los esencialismos a los que apelan para justificar antagonismos.

La historiografía política, que revisa la organización administrativa y el proceso del debate por la provincialización iniciada en 1955 (Arias 2010; Iuorno y Crespo 2008; Varela 2015), está atravesada por esta tensión. Estos estudios disputan sentidos y pertenencias, recorriendo las dificultades de las sociedades locales por lograr reconocimiento, aun en períodos de aperturas de derechos políticos (Mases y Rafart 2003, Barros 2009). En esta línea se destacan las investigaciones de Nicoletti (2012), quien distingue instituciones eventuales en la construcción de una estatalidad que, antes que incompleta, se apoya en formas alternativas. Nicoletti observa la relevancia de la acción evangélica salesiana en la estructuración de espacios económicos, que fueron reforzados en el período provincial. La estructura escolar repite la evidencia de un Estado que llega a Patagonia con un formato diferente al territorio central (Teobaldo 2011). Similarmente, Bohoslavsky (2006) y Suárez (2008) reconocen en los elementos disciplinadores claras referencias a una presencia estatal en términos represivos, tempranamente reconocible en el espacio. En relación con ello Muñoz y Muzzopappa (2018) muestran que las alianzas económicas en emprendimientos binacionales habilitaron permisos para que el control de crímenes en poblaciones fronterizas argentinas fuera entregado a agentes chilenos hasta la década del 20, dando cuenta del complejo y cambiante carácter que, desde las diferentes instituciones y sectores, avanzó en la construcción de argentinidad.

\section{Los aportes de la historia ambiental}

En el relato precedente la pregunta por la historia ambiental se desdibuja, pues las referencias a lo ambiental se inscriben en la reducción del entorno a recurso que se supone fuera de lo social. La historia ambiental discute esto y se presenta como una interpelación que cruza conflictos sociales con modificaciones ambientales en escenarios de crisis. En América Latina esto cobra profundidad por haber sido concebida como espacio colonial, vinculada el apelativo del tutelaje al dominio de la racionalidad occidental (Escobar 2007), que en la Patagonia argentina se replicó en el siglo XX en el control previsto desde el gobierno central. El cruce entre colonialismo y naturaleza toca el reconocimiento de pueblos originarios y las dinámicas extractivistas como tópicos recurrentes. Ulloa (2004), desde Colombia, señala que no se pueden entender los reclamos indígenas, y su peso internacional, si no se reconoce el marco de un discurso ambiental ecológico en donde ese reclamo cobra sonoridad. Observa cómo los gobiernos asumen su rol biopolítico de resguardo de la vida en escenarios donde el entorno se erige como agente, y donde los pueblos originarios aparecen como guardianes ancestrales de una vinculación idílica (y falaz) de territorios de frontera armónicos. El problema en esa idealización es que los cruces entre racionalidades son reducidos a antagonismos. 
Sourrouille y Vezub (2014) critican en la historiografía patagónica el foco puesto en antagonismos, porque omite dinámicas de articulación e invisibiliza actores y sentidos al sobredimensionar un aspecto que, aunque esté presente no necesariamente es el único, y en algunos casos no es el principal. Como contracara, las vinculaciones con el ambiente se desdibujan en una epistemología donde la racionalidad instrumental se traslada desde el mercantilismo a la confrontación. Similarmente, Castro (2004) reconoce la necesidad de una historia ambiental latinoamericana que no se reduzca a la denuncia.

El análisis de los extractivismos reconoce en Argentina una larga tradición con varios anclajes en casos patagónicos. Vale destacar la minería (Walter 2008; Blanco y Méndez 2006); la explotación petrolera, donde se muestra la naturalización de la contaminación (Baeza y Chanampa 2016), el fracking (Trpin y Álvaro 2014), o los problemas en el uso del agua en Chile (Herrera y Torrent 2015; Romero et al. 2009) estudiados como reclamos ambientales. Contrariamente, los estudios referentes a la desertificación a causa de la producción ovina no llegan a debatir esta producción (Andrade 2010), considerada natural a pesar de las dificultades ambientales reconocidas.

Sin embargo, la historia ambiental vista en la perspectiva de McNeill (2005) abre otras consideraciones. Una de ellas es que animales, ambientes y personas parecen constituirse como categorías que se estabilizan mutuamente. Esto evidencia el carácter político de cada una de estas categorizaciones.

Pero ello ha llevado a reflexiones que no siempre se articulan. Así, la mirada biológica, en diálogo con trabajos antropológicos, dio lugar a focos de especies amenazadas, y vinculan amenazas y cuidados a costumbres sociales, sin tomar variables sociales. Klier (2018) analiza cómo la biología de la conservación focaliza casos ubicados en áreas naturales protegidas, dejando por fuera a grandes áreas situadas en los escenarios de conflicto más violentos, ligados, por ejemplo, a "los gigantescos emprendimientos de carácter extractivo, los grandes planes de infraestructura y los nuevos sistemas agrarios tendientes al monocultivo" (Svampa y Viale 2014).

La pregunta por la conservación instala la interpelación hacia el manejo de las sociedades actuales, pero su resolución no termina de abandonar la escisión sociedad/naturaleza ni la construcción histórica de la subalternidad. Como ejemplo vale la mención a artículos representativos de publicaciones en la temática. Así, el artículo de Solari et al. (2012) plantea preguntas acerca de la conservación de la ballena azul en el extremo sur continental. En su reflexión, apela a una historia económica que ata la posibilidad del cuidado a la patrimonialización de aquello a cuidar, ligándolo a un modelo turístico como alternativa económica a la industria extractivista salmonera establecida en las costas chilenas. Este caso muestra una interpretación de un valor económico como valor cultural, desconociendo el modo en que estos dispositivos reproducen dinámicas de apropiación desigual, base del uso destructivo que supone sortear.

Otro escrito que da cuenta que la revisión biológica supone una cierta historia económica es la caracterización de las ecorregiones patagónicas de Matteucci (2012). Este trabajo, orientado al ordenamiento territorial, naturaliza el imaginario del desarrollo al plantear que los grupos indígenas de la zona, antes de la "llegada de los europeos... No eran muy avanzados" (Matteucci 2012:558), permitiendo preguntar por atrasado o adelantado respecto de qué, y la silenciosa respuesta de un capitalismo que opera como horizonte del deber-ser. Es un ejemplo de un estudio biológico que describe al ambiente como evidencia de ese orden económico. El escrito de Matteucci muestra el problema de la perspectiva biologicista, pues aunque este artículo considera los avances de los estudios sociales, reitera el lugar del naturalista como obligado a opinar como agente del desarrollo, naturalizando el sitio de privilegio respecto de otros modos de considerar el espacio, reconocido desde los naturalistas del siglo XIX (Lema y Núñez 2019).

La yuxtaposición de conocimientos naturales y sociales, que supone una realidad trascendente apoyada en la escisión sociedad-naturaleza y toma al individuo como foco de estudios en detrimento de epistemologías relacionales (Plumwood 2004) que sitúan al ambiente en un rol de recurso. Así, los problemas están en el foco de la extracción, eclipsando otros niveles de tensiones y reconocimientos. En Chile aparece una similitud en relación con los reclamos acerca de la construcción de represas en acuíferos cordilleranos binacionales. Un punto que resaltan estos trabajos es que las tensiones en las cuencas se relacionan con que el recurso de los acuíferos es privatizable en Chile, situando como núcleo de tensiones el modelo de desarrollo que se supone natural (Romero et al. 2009; Herrera y 
Torrent 2015). En el amplio sur de ambos países, en lugares no necesariamente aledaños, la problemática se repite.

Pero algo más, el carácter fronterizo de la Patagonia andina genera tensiones en la pregunta por el ambiente precisamente porque los límites ambientales no se agotan en los políticos, así como se evidencia en el problema de las cuencas y los planes hidroeléctricos.

Hay varias temáticas, como la trashumancia neuquina (Silla 2009; Padin 2019) u ordenamientos territoriales (Núñez 2015) que reclaman perspectivas binacionales en el estudio de sociedades y ambientes. Pero una de las figuras más analizadas es la de "Parques Nacionales" como constitutiva del espacio limítrofe entre Argentina y Chile (Bessera 2011; Klobock 2014; Méndez 2010; Navarro 2011; Nouzeillies 1999; Núñez 2015; Vejsbjerg et al. 2014; Picone 2019). Lo establecido como ambiente en el Parque Nacional remite a un paisaje representativo del espíritu nacional que en este caso adoptó muchos años una retórica xenófoba. Esta vinculación entre áreas protegidas y nacionalismos es constitutiva de los Parques Nacionales en el mundo. Nash (1970) vinculó la cultura y la democracia norteamericanas al primer Parque Nacional del mundo en Yellowstone, en 1872. Carruthers (2014) muestra el carácter racista de la conformación de los parques nacionales en Sudáfrica, y las tensiones en torno al manejo a partir de la anulación del Apartheid. Frost y Laing (2013) apelan a elementos culturales y burocráticos mostrando que la historia de los Parques Nacionales presenta diferencias que tienen que ver con las construcciones de cada nación.

En Patagonia, la sutileza y mezcla de trazas humanas y no humanas se pierde en relatos donde la obviedad del extractivismo oculta la tenue cotidianeidad. El racismo, en Patagonia, se inscribe en la historia de conquista citada y atraviesa la formación de los Parques Nacionales que llegaron a plantearse como sinónimo de la frontera (Bessera 2011), donde una adscripción étnica se consideró antagónica al desarrollo y al ambiente que representaba ese desarrollo. Méndez y Podlubne (2008) recorren, por ejemplo, la creación de una institución deportiva para enseñar a los pueblos originarios cómo apreciar correctamente el entorno. Esto se alinea con la observación de Haraway (1999) respecto de los pobladores de áreas naturales protegidas, situados como enemigos de su hábitat por no responder al modelo de visitante ilustrado, que Silla (2009) aún reconoce en pobladores trashumantes del norte neuquino, circulando entre legalidades argentinas y chilenas que no terminan de cumplir.

La historiografía patagónica aparece atada a marcos estáticos de conflictos permanentes. La historia ambiental se encuentra concentrada en estudios biológicos y conflictivos, replicando los límites que McNeill reconoce. El reclamo por interpelar a la historia como disciplina, para incorporar como variable cambiante al ambiente, implica que no solo se debe abordar el cambio social sino la vinculación permanente con los entornos y el peso de la producción de conocimiento como ámbitos de reflexión desde el cual inscribir las problemáticas.

\section{A modo de cierre}

Este trabajo observa cómo los sentidos del territorio y del pasado se estabilizan mutuamente. $\mathrm{Si}$ consideramos en este escenario las tradiciones de la historia ambiental propuestas por McNeill (2005), debemos reconocer que parte de las dificultades en los cruces está en que desde todas las disciplinas se asume en forma a-problemática la escisión sociedad-naturaleza que opera en la base del modelo económico, que además de instrumental es individualista.

En tanto el espacio (como territorio, paisaje o ambiente) sea el espacio del desarrollo, concebido en forma excluyente como comercio internacional, las dinámicas de exclusión serán actualizadas, y ello no es solo un tema de antagonismos sociales. También es en parte una construcción que establece desigualdades. No es solo una consecuencia el capitalismo como estructura desigual, sino de la particularidad del capitalismo y la modernidad que se instalan como si fueran parte del territorio que generan. La Patagonia, como caso, permite reconocer a la historia ambiental como un eje fundamental e insoslayable en el análisis de la construcción de los Estados nacionales y la potencialidad del estudio de sus "márgenes" o territorios fronterizos.

Hay una deuda en la articulación entre las ciencias sociales y las naturales, que permite apelar a idealizaciones difícilmente aplicables en el manejo cotidiano, pero que en sí dan cuenta del desafío en la comprensión de los dinamismos socioambientales, que de nuevo pone sobre el tapete la urgencia por la reflexión acerca de esta temática (Castro 2004; Gallini 2005; Palacio 2002; Woerster 2008). 
La pregunta por lo ambiental y lo material, así como la consulta por las mediaciones que configuran la escisión sociedad-naturaleza como disciplinadora, se descubre asociada a una mirada que propicia los antagonismos, como fundamento del utilitarismo y el instrumentalismo. En esta línea la pregunta por la historia ambiental se reconoce frente varios desafíos. La mirada focalizando las disputas, aun cuando tome los conflictos ambientales, no escapa a la lógica de lo antagónico como exclusivamente constituyente del ordenamiento en las regiones marginales.

Posiblemente el carácter tardío de la incorporación de la Patagonia a los Estados nacionales explique por qué la bibliografía recorrida reitere uno de los puntos críticos observados desde la teoría decolonial y subalterna, la Patagonia se explica desde las falencias y los enfrentamientos, lo que lleva a presumir un ideal implícito con el que se reconocen carencias. Villanueva (2019) reclama el reconocimiento de los Territorios Discursivos, para clarificar expectativas que configuran los espacios, tanto como las materialidades. Gallini (2005) señala que el desafío de la historia ambiental es reconocer lo universal del discurso en lo particular que se observa. El problema que se reconoce en la Patagonia es un universal que no termina de correrse de un sitio disciplinador. Aun en el caso donde se plantean superaciones a la mirada centralista, pues se presta más atención a las paradojas de esa mirada que a la construcción de un conocimiento propio.

La historia de la Patagonia se presenta como una historia de faltas, de una modernidad incompleta que resulta una mala copia del ideal. De aquí, la historia ambiental puede pensarse interpelando la interpretación de los anclajes materiales, podría ser una superación en tanto dé lugar a la relevancia de lo casi imperceptible, pero profundamente constitutivo. Las marcas de personas borradas por mareas o vientos, los sutiles cambios permanentes, e incluso la posibilidad misma de lo cotidiano resultan en preguntas que hoy permiten abrir sentidos en el espacio que, indefectiblemente, necesitan desmantelar el relato de un pasado anclado en la permanencia del tutelaje.

\section{Agradecimientos}

A las/os dos comentaristas anónimas/os, por las mejoras al texto inicial propuesto.

\section{Referencias Citadas}

Andrade, L.

2010 Otoño en la Estepa. Ambiente, Ganadería y Vínculos en la Patagonia Austral. La Colmena, Buenos Aires.

Arias, $\mathrm{M}$

2010 "Tensiones en los debates parlamentarios en torno a la provincialización de los Territorios Nacionales durante el primer peronismo". Quinto Sol 14:103-124.DOI: 10.19137/ quintosol

Bachiller, S.

2019 "Extractivism, production and challenge of inequalities in Argentina". Rev. Mex. Sociol 81(3). DOI:10.22201/ iis.01882503p.2019.3.57919.

Baeza, B. y Chanampa, M.

2016 "La naturalización de las problemáticas medioambientales en torno a la explotación petrolera en Comodoro Rivadavia”. Identidades 3(6):07-31.

Bandieri, S.

2005 Historia de la Patagonia. Sudamericana, Buenos Aires. Barros, S.

2009 "Peronismo y politización. Identidades políticas en la emergencia del peronismo en la Patagonia central". Estudios 22:21-48.DOI:10.31050/1852.1568.n22.440.

Bendini, M. y Tsakoumagkos, P.

2000 "Modernización agroindustrial y mercado de trabajo, ¿flexibilización o precarización?”. Estudios del Trabajo 6(12):89-112.
Bessera, E.

2011 "Exequiel Bustillo y la gestión de los Parques Nacionales". En Cultura y Espacio, editado por Pedro Navarro y Walter Delrio, pp.115-125. UNRN, Bariloche.

Blanco, D. y Méndes, J.

2006 "Aproximaciones al análisis de los conflictos ambientales en la Patagonia". Ambiente \& Sociedad IX(2):47-69. DOI:10.1590/S1414-753X2006000200003.

Blanco, G.

2008 "Tierra y ganado en la Patagonia: políticas públicas y conflictividad en las primeras décadas del siglo XX". Anuario Centro de Estudios Históricos 8(8):21-40.

Bohoslavsky, E.

2006 Los Mitos Conspirativos y la Patagonia en Argentina y Chile Durante la Primera Mitad del Siglo XX. Tesis doctoral, Universidad Complutense de Madrid.

Buscaglia, S. y Bianchi, M.

2016 "From Colonial Representation to Materiality: Spanish Settlements on Península Valdes (Patagonian Coast, 17791810)". Historical Archaeology 50(2):69-88.DOI:10.1007/ BF03377326.

Carrizo, G.

2009 "La Patagonia argentina en el período de entreguerras. Acerca de los orígenes de la Zona Militar de Comodoro Rivadavia". Antíteses 2(4):669-691. DOI: 10.5433/1984-3356.2009v2n4p669. 
Carruthers, J.

2019 "Environmental History with an African Edge". En The Edges of Environmental History, editado por Christof Mauch y Libby Robin, pp.9-18. RCC, Munich.

Castro, G.

2004 "De civilización y naturaleza. Notas para el debate sobre historia ambiental latinoamericana". ProcesoS 20:99-113. DOI:10.29078/rp.v1i20.251.

Chiuminatto, P. y del Río, R.

2016 "Patagonia: Retorno a lo desconocido, la paradójica reminiscencia de un paisaje vacío". Magallania 44(1):7383. https://dx.doi.org/10.4067/S0718-22442016000100005

Coronato, $\mathrm{F}$.

2010 El rol de la Ganadería Ovina en la Construcción del Territorio de la Patagonia. Tesis doctoral, Escuela Doctoral ABIES, París.

Cunill, P.

2014 "Desafíos de la geografía histórica en la integración de los andes y las zonas áridas". Diálogo Andino 44:105-122.

Diegues, C.

2005 El mito moderno de la naturaleza intocada. Center for Research on Human Population and Wetlands, San Pablo.

Escalona, D.

2020 "La negociación en los conflictos ambientales y su implicancia en el desarrollo local: caso de la comunidad aymara de Cancosa”. Diálogo Andino 61, 81-91.

Escobar, A.

2007 La invención del Tercer Mundo: Construcción y deconstrucción del desarrollo. El Perro y la Rana, Caracas.

Favaro, O.

1999 Neuquén. La construcción de un orden estatal. CEHEPYC_UNCo, Neuquén.

Foerster, R. y Vezub, J.

2011 "Malón. Ración y nación en las pampas: El factor Juan Manuel de Rosas (1820-1880)". Historia 44:259-286. DOI:10.4067/S0717-71942011000200001.

Fortunato, N.

2005 "El territorio y sus representaciones como fuente de recursos turísticos. Valores fundacionales del concepto de 'Parque Nacional'". Estudios y Perspectivas en Turismo 14(4):314-348

Frost, W. y Laing, J.

2013 "From Yellowstone to Australia and New Zealand: National Parks 2.0". Global Environment 6(12):62-79.

Gallini, S.

2005 "Invitación a la historia ambiental". Tareas 120:5-28.

Girbal, N.

2008 "Desequilibrio regional y políticas públicas agrarias. Argentina 1880-1960". Páginas 1(2) http://revistapaginas. unr.edu.ar/index.php/RevPaginas/article/view/137

Gordillo, G.

2010 "Historias de los bosques que alguna vez fueron pastizales: la producción de la naturaleza en la frontera argentino-paraguaya". Población \& Sociedad 17:59-79. DOI:10.19137/pys.

Harambour, A. y Barrena, J.

2019 Barbarie o justicia en la Patagonia occidental: las violencias coloniales en el ocaso del pueblo kawésqar, finales del siglo XIX e inicios del siglo XX". Historia Crítica 71: 25-48,DOI:10.7440/histcrit71.2019.02
Haraway, D.

1999 "La promesa de los monstruos: una política regeneradora para otros inapropiados/bles". Política y Sociedad 30:121-163.

Herrera, S. y Torrent, J.

2015 "Proyecto Hidroaysén: capitalismo extractivista, regulación estatal y acción colectiva en la Patagonia". POLIS 14(40):1-21.

Iuorno, G. y Crespo, E.

2008 Nuevos Espacios. Nuevos Problemas. Los Territorios Nacionales. UNPa-UNCo, Argentina.

Klier, G.

2018 Tiempos Modernos: un Análisis Sobre los Discursos de la Biología de la Conservación. Tesis doctoral, Universidad de Buenos Aires.

Klubock, T.

2014 La Frontera: Forests and Ecological Conflict in Chile's Frontier Territory. Duke University Press, Durham.

Lema, C. y Núñez, P.

2019 "Destruir para desarrollar: Ciencia Natural y desigualdad en el ordenamiento patagónico". Cuadernos de Geografía 28(2):255-270. DOI: 10.15446/rcdg.v28n2.73527.

Llosa, C.

2020 "Matando a la gallina de los huevos de oro. Las tensiones en el paisaje andino patagónico". En Tierras Secuenciadas, Cordillera Persistente, editado por Guido Galafassi y Gonzalo Barrios, pp.173-197. Extramuros, Buenos Aires.

Masés, E. y Rafart. G.

2003 "La patria peronista en la Norpatagonia". En La Invención del Peronismo en el Interior del País, editado por Darío Macor y Cesar Tcach, pp.385-436. UNL, Santa Fe.

Matteucci, S.

2012 "Ecorregión Estepa Patagónica". En Ecorregiones y Complejos Ecosistémicos Argentinos, editado por Jorge Morello, pp. 549-654. Orientación Gráfica, Buenos Aires.

McNeill, J.

2005 "Naturaleza y cultura de la historia ambiental". Nómadas 22, 12-25.

Méndez, L y Podlubne, A.

2008 “'Atraer para Educar Recreando'. El Proyecto Ayekan Ruca en San Carlos de Bariloche. 1934-1955". Presentado en $3^{\circ}$ Jornadas de Historia de la Patagonia, Bariloche.

Méndez, L. y Muñoz. J.

2013 "Alianzas sectoriales en clave regional. La Norpatagonia argentino-chilena entre 1895 y 1920". En AraucaníaNorpatagonia, compilado por María Nicoletti y Paula Núñez, pp. 152-167. IIDYPCA, Argentina.

Méndez, L.

2010 Estado, Frontera y Turismo. Prometeo, Buenos Aires. Mendonça, M.

2017 "Monzón sudamericano: la integración de la circulación amazónica y altiplánica y las variabilidades climáticas del altiplano andino chileno". Diálogo Andino 54:21-30.

Muñoz, J. y Muzzopappa, E.

2018 "Orden y comercio. La construcción de Estado y ciudadanía en la cordillera norpatagónica a principios del siglo XX". En Araucanía-Norpatagonia II, editado por Paula Núñez, pp. 25-48. UNRN Editorial,Viedma.

Nash, R.

1970 "The American Invention of National Parks", American Quarterl 22-3:726-735.DOI:10.2307/2711623. 
Navarro, $\mathrm{P}$

2007 Paisajes del Progreso. Educo, Neuquén.

Navarro, $P$.

2004 Patagonia. Ciencia y Conquista. Educo, Neuquén.

Navarro, $P$.

2011 "Territorios marginales: Los desiertos inventados latinoamericanos. Representaciones controvertidas, fragmentadas y resignificadas". En Los desiertos en la Historia de América, coordinado por Deni Trejo, pp. 207-226. Universidad SN de Hidalgo, México.

Nicoletti, M.

2012 "La Patagonia como territorio en disputa. Tensiones entre el Estado, la Iglesia y la congregación salesiana por el espacio misionero". Cultura y Educación VI:183-203.

Nouzeillies, G.

1999 "Patagonia as a Borderland: Nature, Culture and the idea of State". Latin American Cultural Studies 8(1):35-49. DOI: 10.1080/13569329909361947

Núñez, A.; Aliste, E.; Bello, Á. y Osorio, M.

2017 Imaginarios Geográficos, Prácticas y Discursos de Frontera. UCCH, Chile.

Núñez, A.

2013 "La frontera no deja ver la montaña: invisibilización de la cordillera de Los Andes en la Norpatagonia chilenoargentina". Norte Grande, (55), 89-108.

Núñez, A. G., Molina, R., Aliste, E., y Bello, A.

2016 "Silencios geográficos de Patagonia-Aysén: Territorio, nomadismo y perspectivas para re-pensar los márgenes de la nación en el siglo XIX”. Magallania 44(2): 107-130.

Núñez, $\mathrm{P}$

2016 Sombras del Desarrollo. IIDYPCA, Bariloche.

Núñez, P.

2015 "The 'She-Land', social consequences of the sexualized construction of landscape in North Patagonia". Gender, Place and Culture 22(10):1445-1462. DOI: 10.1080/0966369X.2014.991695.

Nuñez, P.; Lema, C. y Michel, C.

2019 "La animalidad patagónica y la modernidad marginal”. Tabula Rasa 32:81-101.DOI: https://doi. org/10.25058/20112742.n32.05

Padin, N.

2019 “'El hombre es tierra que anda'. Los crianceros trashumantes del Alto Neuquén en perspectiva histórica, siglos XIX-XX”. Estudios 41:129-153.

Palacio, G.

2002 "Historia tropical: a reconsiderar las nociones de espacio, tiempo y ciencia". En Repensando la Naturaleza, editado por Germán Palacio y Astrid Ulloa, pp. 67-89. Colciencias, Colombia.

Pérez, P.

2011 "Políticas para la Patagonia en la salida de la gran guerra: el estado y sus márgenes". TEFROS 9. http://www. hum.unrc.edu.ar/ojs/index.php/tefros/article/view/236/217

Picone, $\mathrm{M}$

2019 Landscaping Patagonia: A Spatial History of Nationmaking in the Northern Patagonian Andes, 1895-1945. Tesis doctoral. Emory University.

Plumwood, V.

2004 "Feminismo y Ecología ¿Artemisa versus Gaia?". En Mujeres y Ecología coordinado por María Cavana pp. 53-106. Asociación Cultural Al-Mudayna, Madrid.
Rey, $\mathrm{H}$.

2005 La cordillera Rionegrina. Economía, Estado y Sociedad en la Primera Mitad del Siglo XX. 2010-Bicentenario, Viedma.

Romero Toledo, H.; Romero Aravena, H. y Toledo, X.

2009 "Agua, poder y discursos en el conflicto socioterritorial por la construcción de represas hidroeléctricas en la Patagonia Chilena”. Estudios Americanos 66(2), 81-103.

Ruffini, M. y Luis B.

2013 "La provincialización postergada de la Patagonia argentina (1955-1958)". Temas y Debates 25(7):59-81.

Sarmiento, D.

1874 Facundo o civilización i barbarie. Hachette, Paris.

Sarobe, J.

1935 La Patagonia y sus Problemas. Aniceto López, Buenos Aires.

Serje, $M$.

2005 El Revés de la Nación. Uniandes, Bogotá.

Serrano, J.

2014 "El regionalismo patagónico y los ausentes de la historia en Paisaje en comunidades de pescadores artesanales en una porción de la Patagonia”. En Conocimiento, Paisaje, Territorio, compilado por Hebe Vessuri y Gerardo Bocco, pp. 63-88. UNPA-UNAM-UNRN, Río Gallegos.

Silla, R.

2009 "Identidad, intercambio y aventura en el Alto Neuquén". Intersecciones en Antropología 10:267-278.

Solari, M.; Skewes, J.; Navarro, M. y Paillacheo, F.

2012 "Historia ambiental de los archipiélagos de la Trapananda (Patagonia septentrional, Chile): desafíos para la conservación de la ballena azul". CUHSO 22(1):115-130.DOI:10.7770/ CUHSO-V22N1-ART357.

Soluri, J., Leal, C. y Pádua, J.

2019 A Living Past: Environmental Histories of Modern Latin America. New York, Oxford: Berghahn Books. doi:10.2307/j. ctvw04gzn

Sourrouille, M. y Vezub,J.

2014 “LLargos peregrinajes en el vacío? Indagaciones sobre desplazamientos de indígenas y colonos en la Patagonia central". En Conocimiento, Paisaje, Territorio, compilado por Hebe Vessuri y Gerardo Bocco, pp. 93.115. UNPAUNAM-UNRN, Río Gallegos.

Suárez, G.

2008 "El bandolerismo y la policía fronteriza en la región andina rionegrina, 1911-1912". Estudios Trasandinos 14(2):59-75

Svampa, M. y Viale, E.

2014 Maldesarrollo. La Argentina del Extractivismo y el Despojo. Katz Conocimiento, Argentina.

Tapia, A.

2017 "El diálogo entre cultura y naturaleza como estrategia para la adaptación al cambio y variabilidad climática en el altiplano del norte chileno". Diálogo Andino 54:3-5.

Teobaldo, M.

2011 ;Buenos días, Sr. Inspector! Historia de los Inspectores Escolares en la Patagonia Norte: Río Negro y Neuquén. Perfil y Funciones (1884-1962). Córdoba: FFH-UNC.

Trejo, D

2011 Los Desiertos en la Historia de América. Universidad SN de Hidal, México.

Trpin, V. y Alvaro, B.

2014 "Condiciones productivas locales y exigencias para la comercialización: Transformaciones en la fruticultura 
del norte de la Patagonia argentina”. Pampa 10:193-217. DOI:10.14409/pampa.v1i10.4537.

Trpin, V.; Rodrigues, M.

2018 "Transformaciones territoriales y desigualdades en el norte de la Patagonia: extractivismo y conflictos en áreas agrarias y turísticas". Albuquerque 10(20). DOI: https:// doi.org/10.46401/ajh.2018.v10.7185

Ulloa, A.

2004 La Construcción del Nativo Ecológico. Colciencias, Colombia.

Varela, M.

2015 Estado y Territorios Nacionales. Relaciones, Tensiones y Conflictos en la Sociedad y la Política Rionegrina (19161943). Tesis Doctoral, Universidad Nacional de La Plata.

Vejsbjerg, L.; Núñez, P. y Matossian,B.

2014 "Transformation of Frontier National Parks into Tourism Sites. The North Andean Patagonia Experience (1934-1955)". Almatourism 5(10). DOI:10.1080/10260210108456060.

Vezub, J.

2009 Valentín Saygüeque y la "Gobernación Indígena de Las Manzanas". Poder y Etnicidad en la Patagonia Septentrional (1860-1881). Prometeo, Argentina.
Villanueva, S.

2019 "Aproximación metodológica al concepto de territorios discursivos". Diálogo Andino 59: 55-63.

Walter, $\mathrm{M}$.

2008 "Nuevos conflictos ambientales mineros en Argentina. El caso Esquel (2002-2003)". Revista Iberoamericana de Economía Ecológica 8:15-28.

Williams, G. y Baeza,B.

2018 "Constructores de soberanía en la frontera: la presencia galesa en el discurso oficial provincial chubutense". En Araucanía-Norpatagonia II, editado por Paula Núñez, 381-402. Ediciones, Viedma.

Willis, B.

1914 El Norte de la Patagonia. Naturaleza y Riquezas. Scribner Press, EEUU.

Worster, D.

2008 Transformaciones de la Tierra. Coscoroba, Uruguay. Zusman, P.

2001 "Entre el lugar y la línea: la constitución de las fronteras coloniales patagónicas 1780-1792". Fronteras de la Historia 6:41-67.

Nota

1 El primer reconocimiento de jurisdicción argentina sobre la Patagonia es la Ley 28-1862, que dispuso que fueran nacionales todos los territorios existentes fuera de los límites de las provincias. En 1867 se firmó la Ley de apropiación efectiva del Estado sobre las costas de los ríos patagónicos Negro y Neuquén (Ley 215) y en 1878 se creó la Gobernación de la Patagonia (Ley 954). El territorio de esta gobernación se extendía desde el río Negro y su cuenca hasta el Cabo de Hornos. Su capital fue Mercedes de Patagones (hoy Viedma). 